\title{
Application Research on Multimedia Information Technology in the Universities Physical Teaching
}

\author{
Peng Gao*
}

School of Physical Education, Yanan University, Yanan 716000,Shaanxi, China

\begin{abstract}
Multimedia information education is along with the computer network technology development and appear of a new type of teaching mode, the domestic sports also has been committed to exploring network education technology and college physical teaching integration research. The development of modern science and technology, effectively improving the development of undertakings of physical culture and sports, especially in the area of sports information, the intervention of computer multimedia technology, has realized the rapid acquisition of all kinds of information, processing and integration and sharing. Spot investigation, questionnaire investigation, this paper uses the methods of comparative analysis to describe the multimedia information technology education in the universities sports teaching the application of the status quo, analysis of the application of the multimedia information technology education in colleges and universities physical teaching mode, advantages and existing problems of teaching, makes judgments for the role of network teaching in the universities physical teaching and provides theoretical and practical significance.
\end{abstract}

Keywords: Application research, colleges physical teaching, multimedia technology, physical education curriculum, teaching mode.

\section{INTRODUCTION}

Multimedia technology applied in the field of sports information, is to realize the sports information completeness, timeliness and modern methods of reality, society and the popularization of computer network technology, rapid development has become the multimedia technology in the field of sports information in the application of the booster, constant research and improvement of multimedia information system, it is very necessary. Because of sports information itself except words and pictures, there are a lot of video and audio information, in addition, in recent years, the vigorous development of the sports field in China, makes the number of sports information, growing scientific uses the multimedia technology, implementation of the processing of sports information, has become the current trend of the development of sports information system [1-5].

Multimedia information technology refers to the students under teacher's guidance and cooperation, the use of computer network technology and learning guidance and information resources, and adopts effective way to achieve learning goals of the new education pattern, which mainly involves computer technology, multimedia technology and network interactive technology, etc. In 1995, the international association of remote education network education for the first time the world conference in the UK; in 1989, the organization for economic cooperation and development of education research and discovery center published a paper, "information technology in education". The economic developed countries such as the United States, Britain and Australia have been carried out network education; physical education modernization is the inevitable trend in the social development. Network education technology applied in the sports teaching is an important symbol of modern sports teaching, sports network or the network will be a bright symbol of sports modernization [6-10]. Development of education of sports resources in network, the advantages of application of multimedia technology and improve the quality of physical education teaching, optimize teaching management, has become a developing direction of modernization of physical education teaching. But in the aspect of network in colleges and universities sports teaching in our country, has not yet formed an independent teaching system, this paper through on-the-spot investigation and so on a variety of forms, to the research and evaluation on the physical network teaching model, the results will be the future sports in our country, the formation of the network teaching system, the development of science and application of important basis.

\section{THE MULTIMEDIA TECHNOLOGY}

Research on multimedia technology, first should understand the meaning of the media, the media refers to carry information carrier, is a kind of expression form of information (Fig. 1). As the name suggests, multimedia is the integration of two or more media and complex technology, refers to rely on computer equipment for a variety of text, data and graphics, image processing and multimedia information integration, storage, can realize the data real-time sharing and use of information by the user's own senses to realize information between the computer and communication technology, people are usually called the multimedia computer 


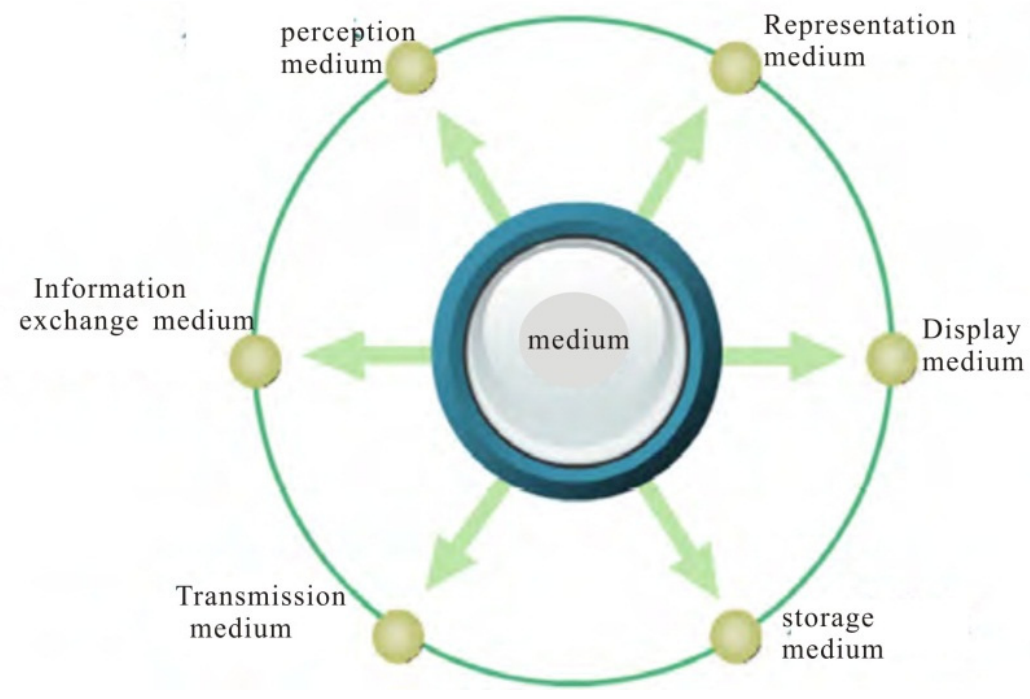

Fig. (1). Media intuitive schematic diagram.

technology, the technology is a blend of two or more media medium, has the following features: (1) carrying the diversity of information means, in short, is refers to the variety of information carrier, if from the point of view, computer is the diversity of information media. (2) Multimedia commutatively, all kinds of information through between the user and the computer exchange behavior, into computer to process and operating data, also, to say the exchange of sex is the most basic characteristics of multimedia technology. (3) Another important feature of their multimedia technology is the integration, due to the system can collect and deal with all kinds of data. Therefore, to realize the processing of these data, must want to rely on the powerful processing system, and this system is centered on computer integrated media integration and the integration of processing all kinds of information processing equipment [11-15]. (4) - digital media in digital form. (5) - sounds, real-time dynamic image (video) change over time.

\section{RESEARCH OBJECTS AND METHODS}

In accordance with the need of this research, in Yanshan University, Shenzhen University, Hunan University of science and technology, a random sample of 300 college students of three universities, completed the questionnaire, discusses college students in the college physical education class settings and traditional recognition degree. This article uses the research methods of literature, field investigation, questionnaire survey, comprehensive analysis method.

\section{RESULT AND ANALYSIS}

\subsection{Physical Teaching Present Situation and the Neces- sity of Multimedia Teaching}

In the mid-1980s, physical teaching reform in colleges and universities to make most of the adopted the public physical education in higher education teaching methods, to improve the enthusiasm of teaching and learning, but some problems still exist: (1) a single teaching content. The contents of the traditional school teaching basic for three big ball, ball, martial arts, aerobics, fitness, swimming, and so on more than ten items are common and popular sport project, not content set widely and arranging a large amount of physical exercise. The teaching content set already unable to meet the contemporary college students and individual character is dye-in-the-wood wide interest hobby. (2) The teaching class hour less. In 1979 the ministry of education promulgated the "ordinary high school physical education teaching outline" regulation of college public physical education classes for 140 hours and 2002 "national ordinary higher school physical education curriculum teaching instruction summary" regulations compulsory system of public physical education in colleges and universities for two years, period is set to 144 hours, the total school no change, the basic lesson once a week. Questionnaire survey was conducted on 300 students showed that $16.33 \%$ of students think that the current sports "deviate too little," $53.67 \%$ of the students think "deviate less"; only $27.33 \%$ and $2.67 \%$ of the students think that is all right "class" and "bullish" (Table 1). There are 57. $33 \%$ of students think only relying on traditional classroom teaching cannot meet the demand of their own physical education learning (Table 2). (3) The traditional sports teaching and extracurricular sports lack of contact. The domestic many colleges and universities physical education teachers only pay attention to the completion of the task of physical education in the classroom students extracurricular physical exercises of organization, management, guide the lack of awareness, the student class -odd exercise laissez faire.

Some characteristics of the technique of network education just can make up for the shortage. Rich sports network teaching material and learn the characteristics of asynchronous teaching time unlimited determines it can undertake sports learning outside the classroom, become a kind of extension of sports class, to develop the students' learning content and learning time. Teacher can also through the network interactive technologies asynchronous to guide the students' sports exercise and learning after class, so that students in a class to be able to obtain knowledge as well as classroom teaching of sports. The application of the network education technology to the current physical education teaching in class, the problem of a class is a good solution. 
Table 1. Questionnaire of students for physical education attitude.

\begin{tabular}{|c|c|c|}
\hline Content Selection & Numbers & Proportion \\
\hline \hline Class number is too little & 49 & $16.33 \%$ \\
\hline Class number is less & 161 & $53.67 \%$ \\
\hline Class number is just right & 82 & $27.33 \%$ \\
\hline Class number is more & 8 & $2.67 \%$ \\
\hline
\end{tabular}

Table 2. Student identification for traditional physical education.

\begin{tabular}{|c|c|c|}
\hline Content Selection & Numbers & Proportion \\
\hline \hline cannot & 172 & $57.33 \%$ \\
\hline Basically & 119 & $39.67 \%$ \\
\hline Absolutely & 9 & $3.00 \%$ \\
\hline
\end{tabular}

Table 3. Multimedia teaching evaluation index.

\begin{tabular}{|c|c|}
\hline Index (Proportion) & Introductions \\
\hline \hline Attendance rate (10\%) & Entry shall be conducted by teachers in the final \\
\hline Online theory achievement (20\%) & More than 10 meter full marks For each 10 points \\
\hline Network Number of use (20\%) & Answer in a full marks \\
\hline Teaching Answering questions (10\%) & According to the BBS of integral block management \\
\hline System communication (40\%) & According to browse and download times score \\
\hline Application Extracurricular learning (20\%) & According to the students to upload useful data points \\
\hline Circumstance (20\%) Resource sharing (10\%) & Assessment of action still is the core \\
\hline Assessment of the action (5) & \\
\hline
\end{tabular}

\subsection{Physical Teaching Mode Analysis under Multimedia Technology}

In current network teaching in domestic universities sports teaching has not yet formed an independent teaching system, to carry out the teaching experiment of the school network teaching as a whole part of the physical education teaching mode, a kind of means. This kind of teaching mode includes online learning, three systems of classroom teaching and extracurricular activities. So here for the evaluation of the effect of network teaching refers to the whole teaching system under the network environment effect evaluation. For the design of evaluation index and specification is as shown in Table 3. Studies have shown that two kinds of teaching mode under network environment have the certain superiority in the teaching effect. Main show is as follows:

\subsubsection{Direct Effect}

The results show that the three schools in terms of physical education teaching contents, based on network technology, with the aid of network resources, widen the teaching content. Yanshan University and utilization of network course selection, teaching and performance, etc., has opened 26 projects of Shenzhen university sports teaching, Hunan University of science and technology also use network resources "survival fitness" can't imagine this kind of traditional sports teaching curriculum. In terms of teaching object, the same faculty condition, auxiliary teaching using the network education technology, it can be finished at the same time several times higher than that of the traditional teaching students knowledge of sports theory and special theory study, improve the efficiency of teaching, the students learning process become more simple, can at any time, place, from any chapter started learning any sports content, can be repeated learning, jumping, and using the Internet query relevant knowledge repository outside the college. Can see clearly from the Table 4 sports network teaching than the traditional sports teaching is more advantageous to the teaching content of mastery.

Studies have shown that network auxiliary teaching environment of physical education on students' physical education learning ability, lifelong sports consciousness and rich knowledge of the role of obvious. "New curriculum stan- 
Table 4. Comparison of traditional physical teaching and multimedia teaching characteristics.

\begin{tabular}{|c|c|}
\hline Traditional Physical Teaching & Multimedia Teaching \\
\hline \hline teacher's guidance & Students explore \\
\hline Lecture teaching & Interactive guide \\
\hline Single subject of isolated from sight teaching module & Multidisciplinary extension module with practical tasks \\
\hline $\begin{array}{c}\text { The teacher as the giver of knowledge } \\
\text { Homogeneous Grouping }\end{array}$ & The teachers for help to promote heterogeneity grouping \\
\hline In view of the factual knowledge and discrete skill assessment & Based on the performance evaluation \\
\hline
\end{tabular}

dard" clearly put forward the "through the Internet access to sports and health knowledge and methods of the ability" as the level of the physical education on students' social adaptation ability training objectives. Pay attention to the students to use network resources under the network teaching environment for autonomous learning, from a certain extent, this benefits to achieve the goal of physical education in the field.

\subsubsection{Indirect Effect}

The application of the network education technology would lead to a great change of the traditional teaching mode, through the new teaching model of indirect role in school sports goal. The experimental group and the control group students has been for two years of follow-up evaluation, found that the physical conditions of students' sports participation and teaching mode and the control group was significantly difference, is superior to the traditional sports teaching. The evaluation of students' body quality includes two aspects of students physical exercise, exercise after class. Strengthen students' physique for school sports goal is one of the first; for sports teaching goal is secondary. Under the network environment of the sports teaching not to establish "strengthen students' physique" to be the principal goal of physical education teaching, but focus more on cultivating students' consciousness and habit of exercise, and awareness of sports functions, and achieve enhanced physique in the form of free exercise of school physical education basic goal. Network teaching mode of physical education through network management to student's extracurricular learning and after-school exercises offer certain mandatory, is advantageous to the student extracurricular physical exercise habits. As the student sports study self-consciousness, physical exercise habits, the teaching mode of "enhanced physique of students gradually emerge and show some delayed. At the same time, the new teaching mode under the network environment for the realization of "strengthening physique" is not entirely dependent on the advantage of network teaching, but with many factors such as the sports teaching mode reform itself together, have a positive impact to the students. The application of the network education technology brought conditions for sports teaching mode reform, and its implicit function by the new teaching mode.

\subsection{Physical Network Teaching Existing Problems in Colleges}

Network teaching needs to establish certain teaching situation, use network resources platform, collaborative and autonomous learning. Network autonomous learning is learners and online learning materials, teachers, classmates one-to-many interactive, it is not absolute isolation study; and self-study is one-on-one interaction between learners and learning materials, there is no the participation of teachers and peers. But because most of the teachers did not accept the network teaching of skills training, so in the teaching process, teachers cannot be carried out on the course as a whole and organization. Teachers' own quality is limited, the network curriculum organization, goal setting is difficult to strictly follow the teaching pattern. The teacher in the teaching goal, teaching process control and the education of developing network teaching thought there is a certain deviation.

During October 9, 2006, in the research of three colleges and universities and information feedback results show that the physical education teachers ignore the impart learning methods, ignore the interaction of application, complete the student to the computer network, the lack of students' autonomous learning process monitoring. Abandoned in the evaluation of student performance in the network teaching should be based on performance evaluation, should make an objective and fair evaluation became the tool of students opportunistic, lost the physical network teaching the teaching advantages.

Physical education teaching in colleges and universities to step into the information process, you must put the sports network information resources development and utilization in the first place. In the universities physical teaching according to different application target, set up different material properties of the material library, in a certain sense, is the implementation of physical education in the network. In the development of network technology in the teaching of physical education function at the same time, also met a lot of problems. The students and teachers generally reflect the sports material quality problem, has become the main problems affecting the effect of network teaching. Survey also shows that only $17.4 \%$ of students satisfied with the campus network of sports material production level. At present the domestic various universities sports sites and sports project learning website there are many problems existing in the sports teaching material.

(1) Of project-based learning website and domestic colleges and universities sports teaching a lot of material on the website is only the original physical textbooks to realize a simple "move", rarely provide heuristic teaching method in 


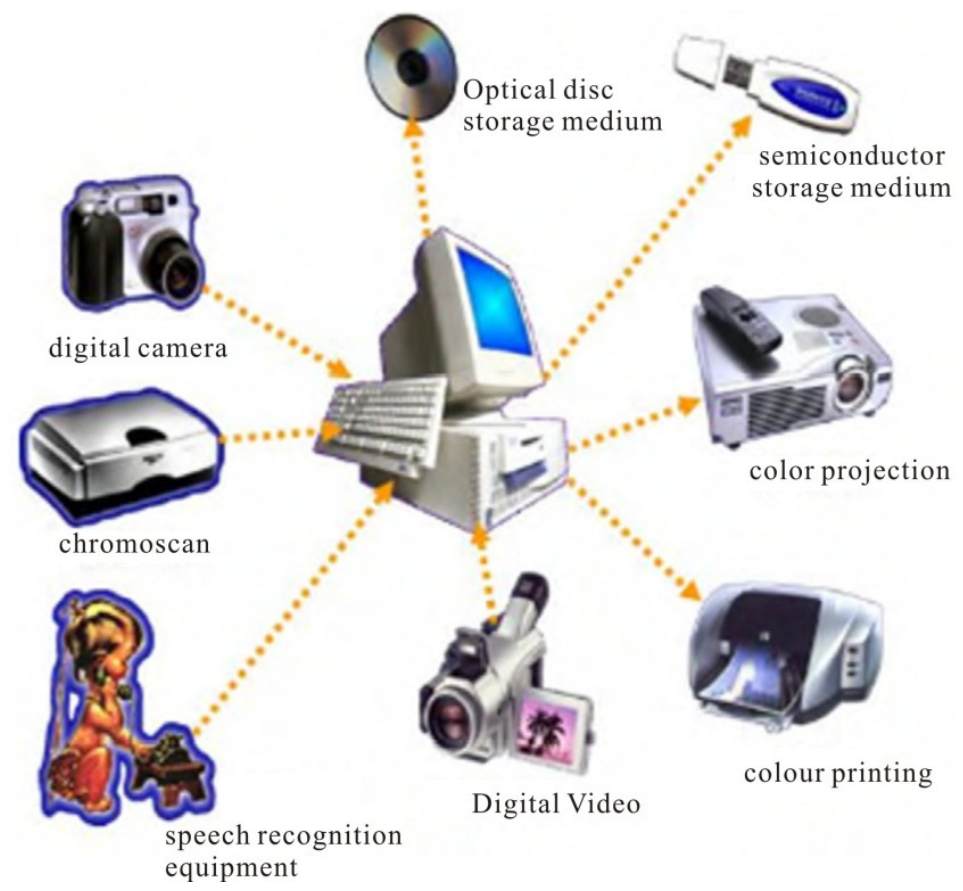

Fig. (2). Multimedia information technology teaching form.

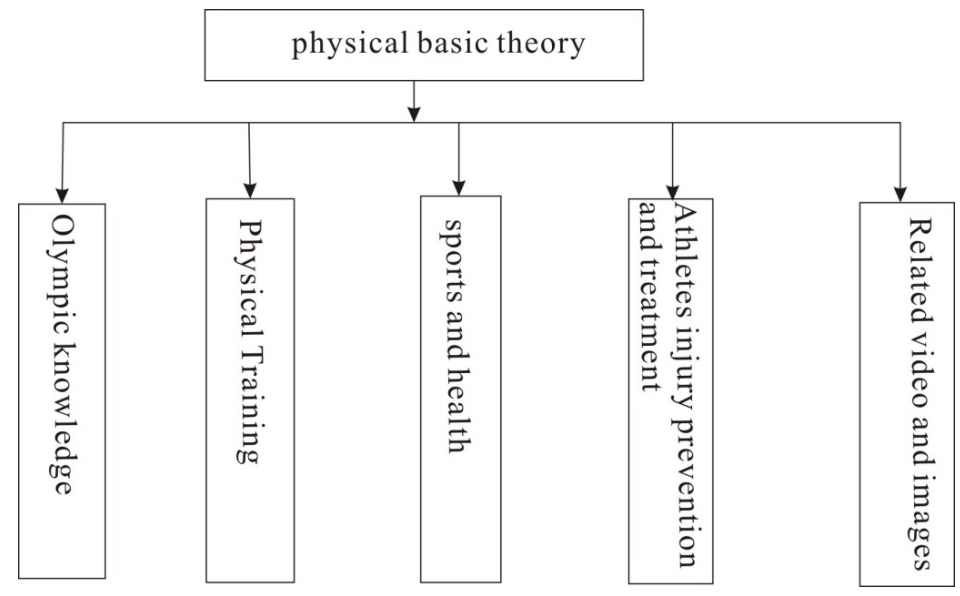

Fig. (3). Multimedia information technology teaching main link.

teaching material, control of the learning process is mainly in computer side: sports network material design cannot reflect their aptitude and individualized learning network teaching thought.

(2) Students use network resources for independent learning, visitor and teachers, visitor and the visitor, communication and coordination between visitor and resource is particularly important. But at present domestic universities sports teaching website for teachers and students in the use of interactive methods, and most of the interactive system is in a state of "idle", make the network teaching lost a very important part of the teaching process.

(3) The multimedia teaching resources is conducive to sports important features of the network learning. It relies mainly on the text, voice, images, animation, film and TV clips. But in domestic colleges and universities sports teaching material performance form too one fold, rarely combined several ways (Fig. 2). From the law embodied, the material expression techniques and communication coordination level, the domestic development of college physical education learning website is a less mature period. This is also in the physical network teaching one of the most fundamental technical problems.

\section{THE APPLICATION OF MULTIMEDIA INFOR- MATION TECHNOLOGY IN THE UNIVERSITIES PHYSICAL TEACHING}

Physical teaching requires students to master a lot of action, and the use of animation image can show the rotation, moving, for the difficult can also slow play or repeated, can let students intuitive understanding each movement trajectory and space position change of parts of the body. Traditional sports teaching is to rely on textbooks on static pictures to show the action, if teachers explain or demonstration is flawed, then it will influence the teaching effect, and the use of multimedia information technology can solve these 
problems. Teachers can be collected from the Internet video, pictures, sounds, etc., used in the teaching in inserts them into the courseware applied in physical education teaching. In the teaching process teachers can slow or repeat playback, video, images can also be treated in text, make the teaching process "action", the process of facilitating students to understand memory and imitation.

Computer is an interactive, and teachers can use this feature to improve the teaching effect. The interpretation of the rules of football, for example, in order to let students understand the concepts of offside, can use the computer to write some interactive practice: in the picture, there are two linesman, another don't lift a hand flag, requests the student to choose says that a linesman offside, if a student answer wrong, will pop-up dialog box, and the next one encouraging words and button; If students correct answer, also the pop-up dialog box, there are words of praise and the next button. Teachers can speak excellent athletes and ordinary athlete motion pictures show come out, let the student analysis and comparison, find the differences and analyzes their action of can help students improve the sports action (Fig. 3).

\section{CONCLUSION}

Physical network teaching than the traditional physical teaching has certain advantages. Network teaching is not only greatly change the students' sports knowledge source structure and the approach to learning, and to training students' physical education learning ability, has an obvious role in promoting the lifelong learning habit; Network teaching can make up for the traditional single teaching content, the defect of too little; Network education technology of the asynchronous nature of teaching and modern teaching means the exploration of new school sports teaching mode and the deepening of teaching reform. Network education technology application in the extracurricular sports a huge space for development. The asynchronous teaching function of network teaching management and guidance of school extracurricular sports, auxiliary students' physical education learning, extension of school physical education class, therefore has the very big development space.

Network education technology in the sports teaching the application also has its limitations. Based on considerations of school physical education basic goal, sports network teaching can optimize the effect of physical education teaching in some respects, part of the sports teaching goal, cannot exist as an independent form of teaching and can complement and expand the role of traditional teaching mode. The sports sites and online material quantity and quality are the priorities for college network education technology development and application problems. In brief, to explore the scientific teaching organization form, improve the teaching quality is the root of the physical network teaching development.

\section{CONFLICT OF INTEREST}

The author confirms that this article content has no conflict of interest.

\section{ACKNOWLEDGEMENTS}

Declared none.

\section{REFERENCES}

[1] S. Deb, "Effective distance learning in developing countries using mobile and multimedia technology", International Journal of Multimedia and Ubiquitous Engineering, vol. 6, no. 2, pp. 33-40, 2011.

[2] C. Jigang, and W. Shixing, "The introduction of multimedia technology into the reform of the traditional methodology", Foreign Language World, vol. 6, p. 001, 2003.

[3] S. Chen, and Y. Xia, "Research on application of multimedia technology in college physical education", Procedia Engineering, vol. 29, pp. 4213-4217, 2012.

[4] J. Mathew Myers, and R. Halpin, "Teachers' attitudes and use of multimedia technology in the classroom: Constructivist-based professional development training for school districts", Journal of Computing in Teacher Education, vol. 18, no. 4, pp. 133-140, 2002.

[5] S. Parks, D. Huot, J. Hamers, and F.H. Lemmonier, "Crossing boundaries: Multimedia technology and pedagogical innovation in a high school class", Language Learning \& Technology, vol. 7, no. 1, pp. 28-45, 2003.

[6] L. Ruiji, "Application Research on the Multimedia Technology in Teaching Reform”, JDCTA: International Journal of Digital Content Technology and its Applications, vol. 6, no. 8, pp. 17-25, 2012.

[7] S. Malik, and A. Agarwal, "Use of multimedia as a new educational technology tool-a study", International Journal of Information and Education Technology, vol. 2, no. 5, pp. 468-471, 2012.

[8] L. Ruiji, "The development on multimedia teaching resources based on information processing theory", International Journal of Advancements in Computing Technology, vol. 4, no. 2, pp. 58-64, 2012.

[9] Q. Chen, "Research for Influence of Physical Education Multimedia Teaching on Sports Motivation of Students", Advances in Information Sciences \& Service Sciences, vol. 4, no. 16, pp. 14-22, 2012.

[10] T. De Jong, M.C. Linn, and Z.C. Zacharia, "Physical and virtual laboratories in science and engineering education", Science, vol. 340, no. 6130, pp. 305-308, 2013.

[11] A. Jackson, L. Gaudet, L. McDaniel, and D. Brammer, "Curriculum integration: The use of technology to support learning", Journal of College Teaching \& Learning, vol. 6, no. 7, 2011.

[12] F.F. Liu, "Computer multimedia technology applied in physical education teaching with intuitionistic fuzzy information", International Journal of Digital Content Technology and its Applications, vol. 6 , no. 23 , p. $119,2012$.

[13] C.D. King, L.A. Lawrence, and G.R. MacKinnon, "Using multimedia technology in Jamaican athletic training education: A casebased learning approach", Journal of Applied Learning Technology, vol. 4, no. 2, pp. 40-49, 2014

[14] M. Papastergiou, "Physical education and sport science undergraduate students as multimedia and web developers: Moving from the user's to the creator's perspective", Education and Information Technologies, vol. 16, no. 3, pp. 281-299, 2011.

[15] Z. Hongdan, "The building of sports E-education platform using multimedia technology", International Journal of Digital Content Technology \& its Applications, vol. 6, no. 14, p. 189, 2012.

\begin{tabular}{lcc}
\hline Received: June 10, 2015 & Revised: July 29, 2015 & Accepted: August 15, 2015 \\
(C) Peng Gao; Licensee Bentham Open. &
\end{tabular}

This is an open access article licensed under the terms of the (https://creativecommons.org/licenses/by/4.0/legalcode), which permits unrestricted, noncommercial use, distribution and reproduction in any medium, provided the work is properly cited. 